\title{
Wingless-type MMTV integration site family (WNT) signalling in pancreatic beta cells-more complex than expected
}

\author{
S. Schinner \\ Received: 26 March 2010 / Accepted: 23 April 2010 /Published online: 6 June 2010 \\ (C) Springer-Verlag 2010
}

Keywords Diabetes mellitus · Islet · TCF7L2 - WNT

signalling

$\begin{array}{ll}\text { Abbreviations } \\ \text { FRP } & \text { Frizzled-related protein } \\ \text { LRP5 } & \text { Low-density lipoprotein receptor-related } \\ & \text { protein 5 } \\ \text { TCF7L2 } & \text { Transcription factor 7-like 2 } \\ \text { WNT } & \text { Wingless-type MMTV integration } \\ & \text { site family }\end{array}$

To the Editor: In 2006 two genome-wide association studies identified a strong association of genetic variants of TCF7L2 with the risk for type 2 diabetes mellitus. In fact, TCF7L2 is, to date, the strongest type 2 diabetes susceptibility gene and the link between this gene and the risk for type 2 diabetes has been confirmed in numerous association studies in various populations. The cumulative data suggest a defect in beta cell function in the carriers of mutations in TCF7L2 as the major underlying cause for the development of diabetes [1].

As this genetic link has been established, the major effort recently has been to understand the function of transcription factor 7-like 2 (TCF7L2) and the related wingless-type MMTV integration site family (WNT)-signalling pathway in beta cells. TCF7L2 is a transcription factor that is coactivated by $\beta$-catenin. $\beta$-Catenin is a crucial signal-

S. Schinner $(\bowtie)$

Department of Endocrinology, Diabetes and Rheumatology,

University Hospital Düsseldorf,

Moorenstr. 5,

40225 Düsseldorf, Germany

e-mail: sven.schinner@uni-duesseldorf.de transduction molecule in the so-called 'canonical' WNTsignalling pathway (see Fig. 1a) [2]. WNT-signalling molecules are expressed on murine and human beta cells and WNT signalling has recently been identified as a regulator of beta cell proliferation and insulin secretion in vitro and in animal studies [3, 4].

The January issue of Diabetologia included an important study by Krützfeldt and Stoffel on the postnatal expression and metabolic regulation of WNT-signalling molecules in pancreatic beta cells in mouse models of obesity [5]. They used Topgal mice to detect canonical WNT signalling in vivo. Surprisingly, using this system they found no detectable canonical WNT signalling in beta cells of wild-type mice and obese $o b / o b$ mice at 2 months of age. Interestingly, the production of WNT4 and frizzledrelated protein (FRP) was shown to be upregulated in beta cells in the mouse model of insulin resistance. When testing the function of WNT4, they found it to act antagonistically to WNT3A in islets with respect to the stabilisation of $\beta$-catenin.

This seems to be in contrast to previous data indicating the crucial role of WNT signalling for beta cell physiology at postnatal stages. A mouse with a knockout of the gene encoding the WNT co-receptor low-density lipoprotein receptor-related protein 5 (LRP5) showed impaired insulin secretion despite normal islet architecture. The underlying defect is most probably impaired sensing of glucose by the affected beta cells [6]. In line with this, molecular studies indicate co-activation of the gene encoding glucokinase-a major regulator of glucose-sensing in beta-cells-by $\beta$-catenin [3]. In addition, knocking down the gene encoding TCF7L2 in adult murine and human islets in vitro reduces beta cell proliferation and insulin secretion [7], emphasising the importance of this transcription factor for beta cell function. Of note, TCF7L2 is a classic target for $\beta$-catenin. 
How can these contrasting findings on the importance of WNT signalling in postnatal islet physiology be explained? One lesson that we can learn from the animal studies in prenatal beta cell development is that accurate timing of the activation of canonical WNT signalling is crucial to allow for normal beta cell function [8]. Similarly, in adult mice, canonical WNT signalling might be switched on and off according to physiological demands at different time points of adult life. Krützfeldt and Stoffel investigated canonical WNT signalling in mice at 2 months of age - this might not reflect other time points in life.

The current data by Krützfeldt and Stoffel suggest that canonical WNT signalling is absent in beta cells of adult mice of a certain age. The question whether non-canonical WNT signalling pathways play a role in beta cell biology is not touched on by this work. In this context it is interesting to note that recent data from basic research studies have questioned our traditional view on the division and specificity of canonical vs non-canonical WNT signalling. Originally, WNT ligands were classified into activators of canonical or non-canonical signalling, implying that the major regulatory event is the presence of specific extracellular ligands. However, data from Amerongen and Nusse suggest a model of receptor-dependent WNT signalling [9]. This implies that the cellular response to WNTs is not only defined by the presence of given WNT ligands at the extracellular site of the cell membrane but also by the receptor context. This includes different frizzled receptors and LRP co-receptors, and also additional receptors for non-canonical WNT signalling. This model lays a particular emphasis on the responsiveness of target cells to WNT signalling in a temporally and spatially controlled manner. In addition, there is substantial intracellular cross-talk between non-canonical and canonical WNT signalling at, for example, the level of $\beta$-catenin.
WNT4 is highly expressed in beta cells, upregulated in obesity and antagonises canonical WNT signalling. What is the physiological relevance of this? Krützfeldt and Stoffel suggest WNT4 might protect beta cells from canonical WNT activation by exogenous WNT ligands. Under in vitro conditions, adipocytes can activate WNT signalling in beta cells [3], but it is not proven whether such cross-talk is possible in vivo. Interestingly, WNT-signalling molecules have been detected in the systemic blood circulation in humans and there is evidence that the WNT antagonist dickkopf 1 (DKK-1), which is detectable in peripheral blood, derives from (among other tissues) adipocytes [10]. This suggests the possibility of paracrine and endocrine actions of WNT-signalling molecules. By secreting WNT4, beta cells could regulate their responsiveness to exogenous WNTs. WNT4 might act as a competitive antagonist to canonical WNTs (see Fig. 1b). Alternatively, it has been demonstrated (although not in beta cells) that WNT4 can inhibit $\beta$-catenin downstream signalling by redirecting it to the cell membrane, thereby preventing its nuclear translocation [11] (see Fig. 1c). However, it remains unclear whether this putative prevention of activation of canonical WNT signalling is involved in diabetes development and, if it is, whether it is a cause or a consequence of beta cell failure.

In conclusion, the important studies on WNT signalling in beta cells during the past years have greatly contributed to our understanding of the physiological role of this pathway in metabolic regulation. These studies have, however, raised even more questions. Currently, there is clear evidence that WNT signalling is an important regulator of beta cell development and function in humans and in murine models. The exact regulatory steps remain to be determined.
Fig. 1 Intracellular WNT signalling. a Activation of canonical WNT signalling by binding of ligands to frizzled receptors and LRP co-receptors. b Competitive antagonism of WNT4 with other WNT ligands prevents downstream actions of $\beta$-catenin. $\mathbf{c}$ WNT4 redirects $\beta$-catenin $(\beta$-cat) to the cell membrane, thereby preventing downstream actions of $\beta$-catenin. The question mark in (c) indicates that it is not yet known which cell surface receptors are involved in mediating this effect. LEF, lymphoid enhancer binding factor

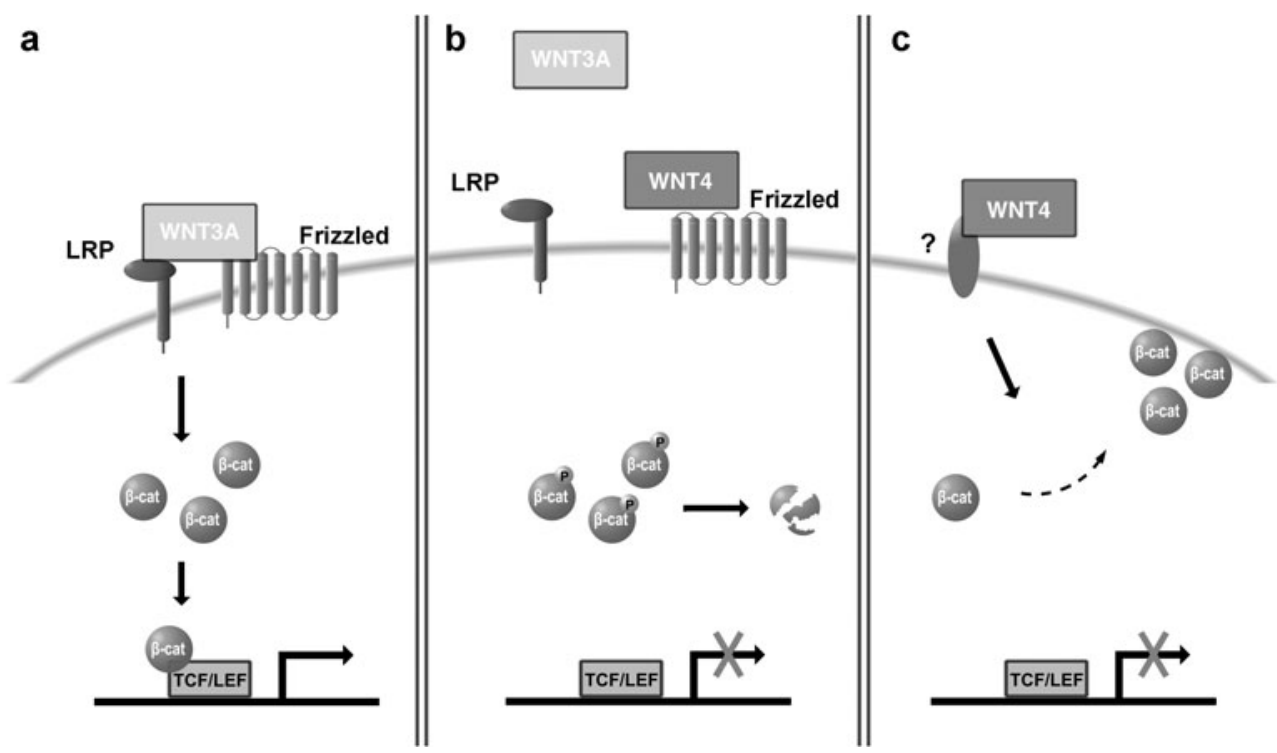


Duality of interest The author declares no duality of interest associated with this manuscript.

\section{References}

1. Lyssenko V, Lupi R, Marchetti P et al (2007) Mechanisms by which common variants in the TCF7L2 gene increase risk of type 2 diabetes. J Clin Invest 117:2155-2163

2. Schinner S, Willenberg HS, Schott M, Scherbaum WA (2009) Pathophysiological aspects of Wnt-signaling in endocrine disease. Eur J Endocrinol 160:731-737

3. Schinner S, Ulgen F, Papewalis C et al (2008) Regulation of insulin secretion, glucokinase gene transcription and beta cell proliferation by adipocyte-derived Wnt signalling molecules. Diabetologia 51:147-154

4. Rulifson IC, Karnik SK, Heiser PW et al (2007) Wnt signaling regulates pancreatic beta cell proliferation. Proc Natl Acad Sci USA 104:6247-6252

5. Krützfeldt J, Stoffel M (2010) Regulation of wingless-type MMTV integration site family (WNT) signalling in pancreatic islets from wild-type and obese mice. Diabetologia 53:123127

6. Fujino T, Asaba H, Kang MJ et al (2003) Low-density lipoprotein receptor-related protein 5 (LRP5) is essential for normal cholesterol metabolism and glucose-induced insulin secretion. Proc Natl Acad Sci USA 100:229-234

7. Shu L, Sauter NS, Schulthess FT, Matveyenko AV, Oberholzer J, Maedler K (2008) Transcription factor 7-like 2 regulates beta-cell survival and function in human pancreatic islets. Diabetes 57:645653

8. Murtaugh LC (2008) The what, where, when and how of Wnt/ beta-catenin signaling in pancreas development. Organogenesis 4:81-86

9. van Amerongen R, Nusse R (2009) Towards an integrated view of Wnt signaling in development. Development 136:3205-3214

10. Gustafson B, Eliasson B, Smith U (2010) Thiazolidinediones increase the wingless-type MMTV integration site family (WNT) inhibitor Dickkopf-1 in adipocytes: a link with osteogenesis. Diabetologia 53:536-540

11. Bernard P, Fleming A, Lacombe A, Harley VR, Vilain E (2008) Wnt4 inhibits beta-catenin/TCF signalling by redirecting betacatenin to the cell membrane. Biol Cell 100:167-177 